\title{
Cr(VI) Determination in Seawater Samples Using an On-line Sorption Preconcentration in a Knotted Reactor Coupled With Electrothermal Atomic Absorption Spectrometry
}

\author{
Paloma Herbello-Hermelo, María del Carmen Barciela-Alonso, and Pilar Bermejo-Barrera* \\ Department of Analytical Chemistry, Nutrition and Bromatology, Faculty of Chemistry, \\ 15782 Santiago de Compostela, Spain
}

\section{INTRODUCTION}

Chromium (Cr) is an estuarine contaminant due to industrial applications such as leather tanning, dyeing, chromium plating, etc., where large volumes of chromium waste in various chemical forms are discharged into the aquatic systems (1). Among the different species, $\mathrm{Cr}(\mathrm{VI})$ is the most toxic form. It is considered a carcinogenic substance due to its high oxidation potential and because it easily permeates biological membranes $(2,3)$. In 1958, the WHO recommended a maximum allowable level of $50 \mu \mathrm{g} \mathrm{L}^{-1}$ in drinking water, which is accepted today within the European Union. On the other hand, the European "Directive Relative to Quality of Water for Keeping Mollusc" (4) established a maximum level of $5 \mu \mathrm{g} \mathrm{L}{ }^{-1}$ of $\mathrm{Cr}(\mathrm{VI})$ in seawater. Thus, highly sensitive and selective techniques are required to determine $\mathrm{Cr}(\mathrm{VI})$ in seawater samples.

To perform Cr(VI) determination, different methods have been applied. For instance, the selective coprecipitation of $\mathrm{Cr}$ (III) with $\mathrm{Fe}(\mathrm{OH})_{3}$ and the subsequent determination of total $\mathrm{Cr}$ prior to the reduction of $\mathrm{Cr}(\mathrm{VI})$ (5). The complex formation with 8-hydroxyquinoline has been used to separate $\mathrm{Cr}(\mathrm{III})$ in a polystyrene-divinylbenzene column with the final determination by ETAAS (6). Other authors $(7,8)$ proposed the determination of Cr(VI) using a FI-FAAS method

${ }^{*}$ Corresponding autbor.

E-mail: pilarbermejo@usc.es

\section{ABSTRACT}

An on-line flow injection sorption preconcencentration in a knotted reactor coupled with electrothermal atomic absorption spectrometry (FI-KR-ETAAS) has been developed to determine chromium(VI) in seawater samples. The on-line complex formation between $\mathrm{Cr}(\mathrm{VI})$ and ammoniumpirrolidindithiocarbamate (APDC) was performed and the complex retained on the inner wall of the KR.

Variables affecting the sorption preconcentration process, such as pH, APDC amount, load flow rate, preconcentration time, concentration and volume of washing solution, KR length, elution volume, and interferences, were studied.

The complex was eluted with $40 \mu \mathrm{L}$ of ethanol and introduced directly into the graphite furnace. A preconcentration factor of 31 was obtained. The detection limit (3SD) was $7 \mathrm{ng} \mathrm{L}^{-1}$. The precision (RSD $\mathrm{n}=11$ ) was $4.4 \%$ at $0.2 \mu \mathrm{g} \mathrm{L}^{-1}$, and the recovery was $99.3 \pm$ $1.70 \%$. The method was applied to the $\mathrm{Cr}(\mathrm{VI})$ determination in seawater samples from the Ria de Arousa Estuarine in Galicia (Northwestern Spain), resulting in $\mathrm{Cr}(\mathrm{VI})$ concentrations ranging from $0.03-0.09 \mu \mathrm{g} \mathrm{L}^{-1}$.

with the selective formation of a complex between $\mathrm{Cr}(\mathrm{VI})$ and ammonium diethyldithiocarbamate (DDTC) and preconcentration in a C18-silica gel column. The liquidliquid extraction using the complex $\mathrm{Cr}(\mathrm{VI})$-ammonium pyrrolidine dithiocarbamate (APDC) in methylisobutyl- ketone (MIBK) was also proposed (9) using a FI-ETAAS system. The use of knotted reactors (KR) has been proposed in order to perform the separation/preconcentration of species in on-line procedures $(10,11,12)$. The KR procedure presents some advantages, such as low cost, easy construction, good stability sorption properties, long lifetime, and easy coupling with different techniques. Nevertheless, the most important fact to consider is that the specie must be in a neutral form and generally requires neutral chelates to perform the preconcentration. In a previous work (13), we developed a method to perform the flow injection online preconcentration in a KR coupled to ETAAS for the selective determination of arsenic (III). In this paper, we developed a procedure for the direct determination of $\mathrm{Cr}(\mathrm{VI})$ in seawater samples by preconcentration of the complex Cr(VI)-APDC in a KR and subsequent direct elution into the graphite furnace.

\section{EXPERIMENTAL}

\section{Instrumentation}

A PerkinElmer ${ }^{\circledR}$ Model 4100ZL atomic absorption spectrometer with a transversely heated graphite tube atomizer (THGA ${ }^{\mathrm{TM}}$ ) and Zeeman-effect background correction, equipped with an AS-71 furnace autosampler, was employed throughout this work (PerkinElmer, Inc., Shelton, CT, USA). A hollow cathode lamp (working at $12 \mathrm{~mA}$ ) for chromium at $357.9 \mathrm{~nm}$ was 
used, and a spectra slit width of $0.7 \mathrm{~nm}$. Standard pyrolytically coated polycrystalline electrographite THGA tubes with an integrated L'vov platform were used.

The spectrometer was operated in the flow injection atomic spectrometry (FIAS) furnace mode controlled by PerkinElmer AAWinLab ${ }^{\mathrm{TM}}$ software 4.01. A PerkinElmer FIAS 400 flow injection system, equipped with two individually controlled peristaltic pumps and a standard rotary injector valve (fourport on the rotor and five-port on the stator), was used for the FI online sorption preconcentration and separation. An additional 6 position/ 6 port selection valve (Rheodyne ${ }^{\circledR}$ ) was used.

Several laboratory-made KRs from PTFE tubing of $0.5 \mathrm{~mm}$ i.d. and different lengths (10, 15, 20, 25 , and $30 \mathrm{~cm}$ ) were used for sorption of the analyte complex. Tygon ${ }^{\circledR}$ pump tubes were employed to propel the sample, reagent, eluent, and air. Different lengths of PTFE tubing were used as the eluent loop. The instrumental operating conditions are listed in Tables I and II.

\section{Reagents and Standard Solutions}

All chemicals used were of ultrapure grade and ultrapure water, resistance $18 \mathrm{M} \Omega \mathrm{cm}^{-1}$, obtained with a Milli-Q purification system (Millipore Corporation, Bedford, MA, USA). A $0.05 \%(\mathrm{~m} / \mathrm{v})$ solution of ammonium pyrrolidine dithiocarbamate (APDC) was prepared daily by dissolution of a $1.0 \%$ stock solution of APDC (Sigma, Germany) in water. A hydrochloric acid $0.05 \mathrm{M}$ solution was prepared by dissolution with hydrochloric acid 35\% Hiperpur ${ }^{\circledR}$ (Panreac, Spain). A washing solution was prepared with APDC $0.05 \%(\mathrm{~m} / \mathrm{v})$ and $\mathrm{HNO}_{3}$ $0.02 \%$ using nitric acid 69\% Hiperpur (Panreac, Spain). Absolute ethanol for analysis (Panreac, Spain) was used as the eluent. This solvent must be distilled at $80{ }^{\circ} \mathrm{C}$ in the laboratory to eliminate the presence of chromium at trace levels.

The stock standard solution of Cr(VI) of $1000 \mathrm{mg} \mathrm{L}^{-1}$ was prepared by dissolving potassium dichromate (99\%) (Aldrich Chemical, USA) and kept at $4{ }^{\circ} \mathrm{C}$ temperature.

Cr(III) stock solution of $1 \mathrm{mg} \mathrm{L}^{-1}$ $\left(\mathrm{Cr}\left(\mathrm{NO}_{3}\right)_{3}\right)$ (Merck, Germany). A synthetic seawater was prepared by dissolving $32 \mathrm{~g}$ of $\mathrm{NaCl}$ for analysis (Merck, Germany), $14 \mathrm{~g}$ of $\mathrm{MgSO}_{4} \cdot 7 \mathrm{H}_{2} \mathrm{O}$ PA-ACS (Panreac, Spain) and $0.15 \mathrm{~g}$ of $\mathrm{NaHCO}_{3}$ for analysis (Merck, Spain), and making the solution up to $1000 \mathrm{~mL}$ volume with ultrapure water. All other reagents used were of analytical grade.
TABLE I

Operating Sequence of FI On-line Preconcentration System for ETAAS Determination of Cr(VI)

\begin{tabular}{llcccll}
\hline Step & Function & $\begin{array}{c}\text { Time } \\
\text { (s) }\end{array}$ & $\begin{array}{c}\text { Pump 1 } \\
\text { (rpm) }\end{array}$ & $\begin{array}{l}\text { Pump } \\
(\mathrm{rpm})\end{array}$ & $\begin{array}{l}\text { Injectn } \\
\text { Valve }\end{array}$ & $\begin{array}{l}\text { Selectn } \\
\text { Valve }\end{array}$ \\
\hline 1 & $\begin{array}{l}\text { Ethanol } \\
\text { Load }\end{array}$ & 3 & 0 & 35 & Load & 1 \\
2 & Elution & 45 & 0 & 20 & Injection & 1 \\
3 & $\begin{array}{l}\text { Preconcen- } \\
\text { tration }\end{array}$ & 60 & 60 & 0 & Injection & 2 \\
4 & $\begin{array}{l}\text { Washing } \\
\text { Solution }\end{array}$ & 10 & 60 & 0 & Injection & 3 \\
5 & Air & 20 & 0 & 60 & Injection & 1 \\
\hline
\end{tabular}

Injectn=Injection, Selectn=Selection.
Argon N50 gas was used as the carrier gas in the atomic absorption spectrometer.

All glassware was soaked for at least 48 hours in 10\% nitric acid and then rinsed in ultrapure water before use.

\section{Procedures}

The flow injection manifold and the operating sequence for the preconcentration and separation steps are show in Table I. Preconcentration was performed in parallel with the ETAAS determination of the previous sample concentration cycle. The ETAAS conditions are listed in Table II.

\section{Flow Injection Procedure}

Hydrochloric acid at $0.01 \mathrm{~mol} \mathrm{~L}^{-1}$ was used to adjust the sample's acidity. The sample flow rate used was $5 \mathrm{~mL} \mathrm{~min}^{-1}$ with a preconcentration time of 120 seconds. The washing solution used after the preconcentration step was a mixture of $0.02 \%(\mathrm{v} / \mathrm{v})$ nitric acid containing $0.01 \%(\mathrm{~m} / \mathrm{v})$ APDC for 10 seconds. The elution volume needed for the quantitative elution is critical for the successful adaptation of the KR sorption separation and preconcentration system to the requirements of ETAAS. To achieve this, the residual rinsing solution in the KR and eluent delivery tube was completely removed using an air flow of $3 \mathrm{~mL} \mathrm{~min} \mathrm{~m}^{-1}$ before elution. The inclusion of air in the pump propelled the flow between the differ-

TABLE II

Temperature and Time Program for the Graphite Furnace

\begin{tabular}{lrrrc}
\hline Step & $\begin{array}{c}\text { Temp. } \\
\left({ }^{\circ} \mathrm{C}\right)\end{array}$ & $\begin{array}{c}\text { Ramp } \\
\text { Time } \\
(\mathrm{s})\end{array}$ & $\begin{array}{c}\text { Hold } \\
\text { Time } \\
(\mathrm{s})\end{array}$ & $\begin{array}{c}\text { Argon } \\
\text { Flow } \\
\left(\mathrm{mL} \mathrm{min}^{-1}\right)\end{array}$ \\
\hline Dry 1 & 90 & 1 & 30 & 250 \\
Dry 2 & 120 & 15 & 30 & 250 \\
Pyrolysis & 1300 & 10 & 20 & 250 \\
Atomization & 2200 & 0 & 5 & 0 \\
Clean & 2450 & 1 & 3 & 250 \\
\hline
\end{tabular}


ent solutions, effectively reducing mutual dispersion between these fluids and significantly improving the efficiency. The KR tube length was $100 \mathrm{~cm}$, and an eluent volume of $40 \mu \mathrm{L}$ was used with an elution

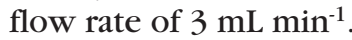

\section{RESULTS AND DISCUSSION}

\section{Optimization of Graphite Furnace Program}

The graphite furnace temperatures were studied in the discontinuous mode with a solution of $3 \mu \mathrm{g} \mathrm{L}^{-1}$ of $\mathrm{Cr}(\mathrm{VI})$ in ethanol. The curves of the pyrolysis and atomization temperatures obtained are shown in Figure 1, with 1300 and $2200{ }^{\circ} \mathrm{C}$ as the optimum temperatures for the pyrolysis and atomization steps, respectively. All other optimized conditions are shown in Table II.

\section{Effect of HCl Concentration}

Since the formation of the Cr(VI)-APDC complex depends on the $\mathrm{pH}$, a set of experiments was performed by applying the preconcentration procedure to a synthetic seawater spiked with $0.2 \mu \mathrm{g} \mathrm{L}^{-1}$ of Cr(VI) with a fixed amount of $0.05 \%(\mathrm{~m} / \mathrm{v})$ APDC concentration and different $\mathrm{HCl}$ concentrations between 0 to $1 \mathrm{M}$. The results obtained are shown in Figure 2. Complex formation was produced with an $\mathrm{HCl}$ of $0.005 \mathrm{M}$, where the absorbance increased until 0.05M. An important decrease in the absorbance signals was observed with higher $\mathrm{HCl}$ concentrations. This is due to a degradation of the APDC or due to a change in the oxidation state of the $\mathrm{Cr}(\mathrm{VI})$. On the other hand, the same experiment was performed using Cr(III) but the absorbance signal was not observed. This confirms that Cr(III) did not form a complex with APDC and that this specie was not preconcentrated in the KR. We

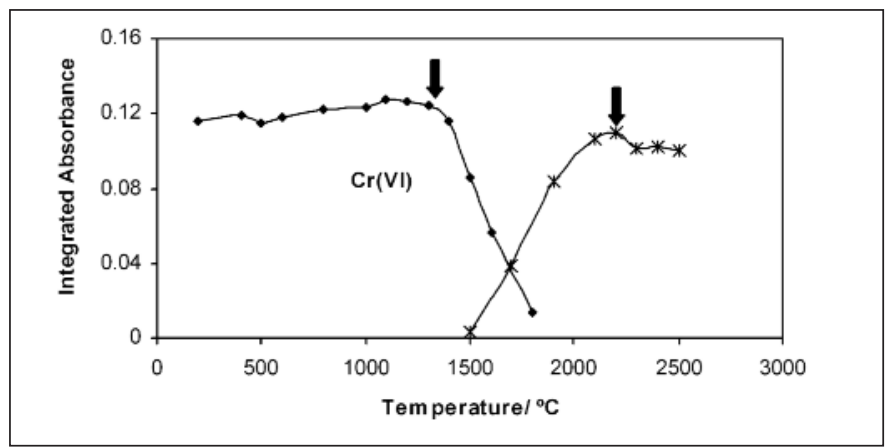

Fig. 1. Pyrolisis and atomization curves for Cr(VI) in ethanol.

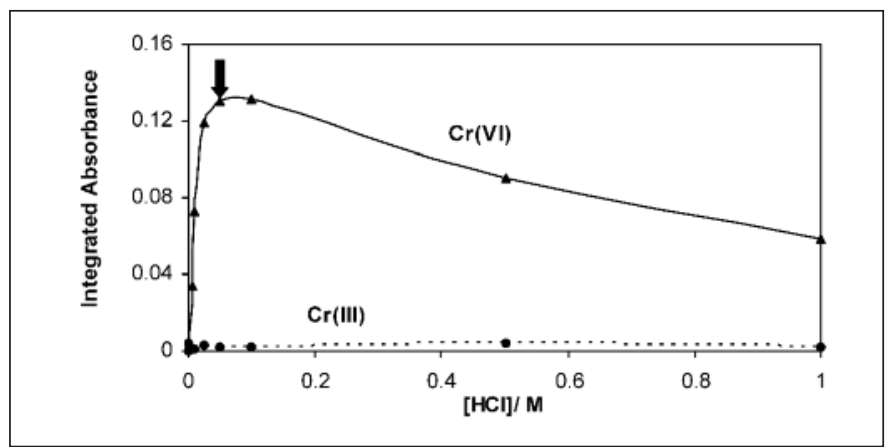

Fig. 2. Effect of the HCl concentrations on the Cr(VI)-APDC complex formation. selected an $\mathrm{HCl}$ concentration of $0.05 \mathrm{M}$ as optimum.

\section{Effect of APDC Concentration}

The influence on the integrated absorbance of APDC concentration ranging from $0-0.1 \%(\mathrm{~m} / \mathrm{v})$ was investigated for a synthetic seawater sample spiked with $0.2 \mu \mathrm{g} \mathrm{\textrm {L } ^ { - 1 }}$ $\mathrm{Cr}(\mathrm{VI})$. The flow rates of the sample, $\mathrm{HCl}$, and APDC solutions were kept constant.

The results obtained are shown in Figure 3. An increase in integrated absorbance with an increase in APDC concentration was observed up to $0.05 \%(\mathrm{~m} / \mathrm{v})$. Without APDC, Cr(VI) was not recovered (as might be expected) because the complex formation and its subsequent sorption on the inner walls of the KR play an important role in the preconcentration. A $0.05 \%(\mathrm{~m} / \mathrm{v})$ APDC concentration was selected as optimum.

\section{Effect of Sample Flow Rate}

The effect of sample flow rate was studied at a fixed APDC flow rate of $1.5 \mathrm{~mL} \mathrm{~min}^{-1}$ with $120 \mathrm{sec}$ onds of preconcentration time. Different sample flow rates were obtained using Tygon ${ }^{\circledR}$ tubes with different internal diameters. Due to the importance of the acidity on the extraction, two sets of experiments were performed: first, using a fixed flow rate of $\mathrm{HCl}$ at $5 \mathrm{~mL} \mathrm{~min}^{-1}$ and, second, with similar flow rates for the sample and the HCl. The

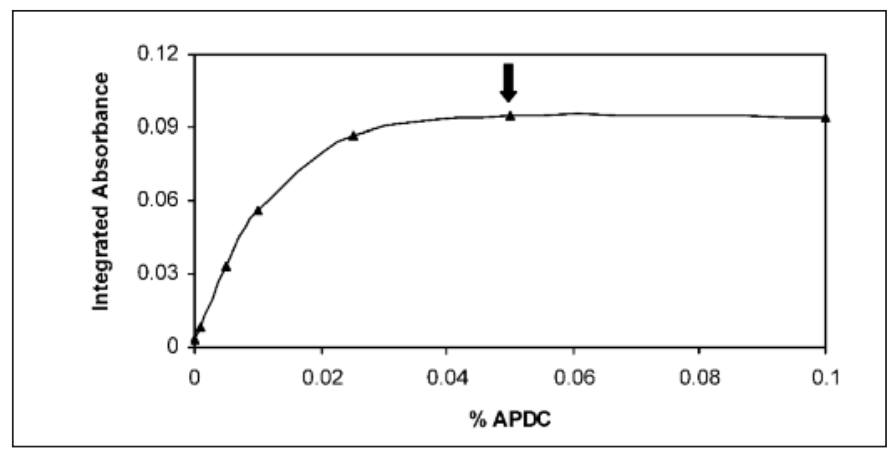

Fig. 3. Effect of the APDC concentrations on the Cr(VI)-APDC complex formation. 
results obtained are shown in Figure 4 . Best results were obtained for a $\mathrm{HCl}$ flow rate of $5 \mathrm{~mL} \mathrm{~min}^{-1}$ and a sample flow rate of $10 \mathrm{~mL} \mathrm{~min}^{-1}$. But in order to use less sample amount and not increase the analysis time, we selected $5 \mathrm{~mL} \mathrm{~min}^{-1}$ as the optimum sample flow rate.

\section{Effect of Preconcentration Time}

The effect of preconcentration time was studied from 10 to 120 seconds using a sample and $\mathrm{HCl}$ flow rate of $5 \mathrm{~mL} \mathrm{~min}{ }^{-1}$ with a synthetic seawater sample spiked with $0.2 \mu \mathrm{g} \mathrm{L}^{-1}$ of $\mathrm{Cr}(\mathrm{VI})$. Good sensitivity was obtained for 120 seconds of preconcentration time and a $10-\mathrm{mL}$ sample volume. This length of time is not a problem for the analysis because preconcentration of one sample and determination of $\mathrm{Cr}(\mathrm{VI})$ in the preceding sample in the graphite furnace are simultaneous.

\section{Effect of Washing Step}

In order to remove the nonadsorbed constituents of the matrix from the KR, an efficient washing step must be performed. A study about the use of Milli-Q ${ }^{\mathrm{TM}}$ water, $0.02 \% \mathrm{HNO}_{3}$, and a mixture $0.01 \%$ APDC $+0.02 \% \mathrm{HNO}_{3}$, including different times from 5 to 60 seconds, was performed. The results obtained are shown in Figure 5. With the use of nitric acid and MilliQ water, some loss of Cr(VI) was observed, and this loss increases with washing time. Thus, we selected the mixture $0.01 \%$ APDC + $0.02 \% \mathrm{HNO}_{3}$. The addition of APDC to the wash solution prevented analyte loss. We concluded that the analyte loss during KR rinsing without APDC in the wash solution could be due to the rapid dissociation of the adsorbed Cr(VI)-APDC complex. The presence of APDC in the washing medium probably inhibited complex dissociation, and therefore, prevented analyte loss.

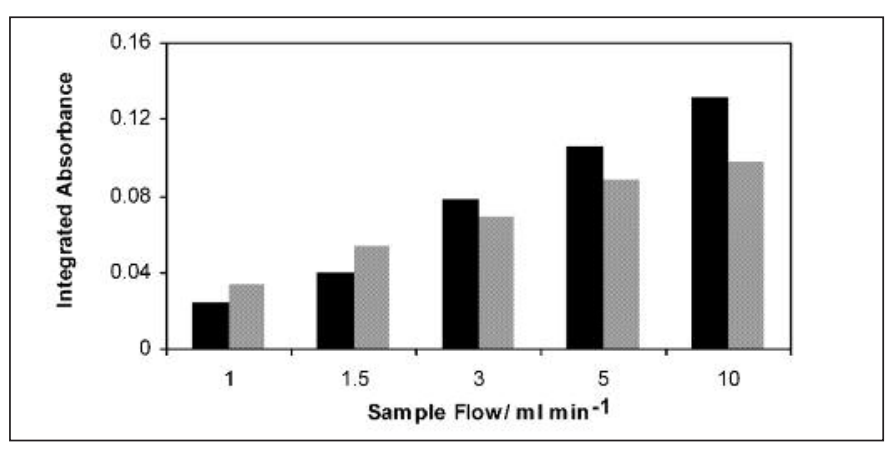

Fig. 4. Effects of the sample flow rate and of the $\mathrm{HCl}$ flow rate on the integrated absorbance.

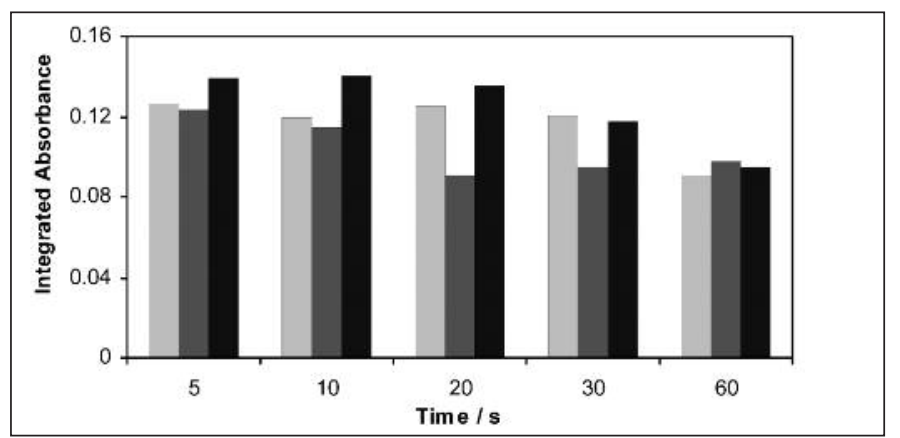

Fig. 5. Influence of wash medium and washing time on integrated absorbance of seawater sample spiked with $0.2 \mu \mathrm{g} \mathrm{L}^{-1}$ of $\operatorname{Cr}(V I)$.
The optimum washing time selected was 10 seconds, because this is the minimum time necessary to wash the KR.

\section{Effect of KR Length and Elution Volume}

The KR tube length, eluent volume, and flow rate for elution was optimized together. Due to the discontinuous mode of the detector in ETAAS, the optimization of the eluent volume required for quantitative elution is a critical parameter. Before elution, the residual washing solution in the KR and eluent delivery tube was completely removed

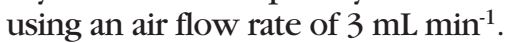
The introduction of air into the pump propelled the flow between the different solutions, and thus reduced the dispersion problems and improved efficiency. The effect of knotted reactor length was studied for $50,75,100,125$, and 200 $\mathrm{cm}$ (with an internal diameter of 0.5 $\mathrm{mm}$ ) and for eluent volumes ranging from 20 to $60 \mu \mathrm{L}$. The results obtained are shown in Figure 6. Maximum integrated absorbance was obtained with a $200 \mathrm{~cm}$ long $\mathrm{KR}$ and an eluent volume of $60 \mu \mathrm{L}$. Nevertheless, this length presented several problems: first, an increase by 1 minute of elution time for each replicate and, second, poor precision in the ETAAS determination due to the irreproducible spreading of the larger ethanolic eluent in the graphite tube. With

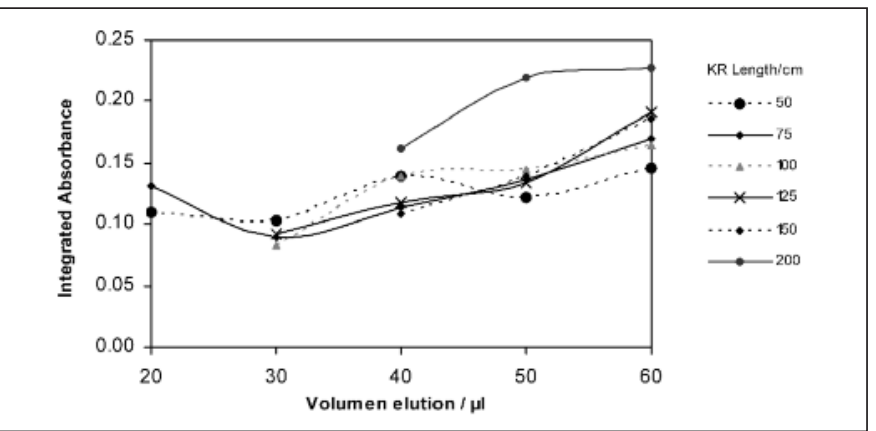

Fig. 6. Effect of the length and elution volume on the absorbance for the determination of Cr(VI) in a seawater sample spiked with $0.2 \mu \mathrm{g} \mathrm{L}^{-1}$. 
the elution volume of $60 \mu \mathrm{L}$, the reproducibility problems were present for all lengths. The $20 \mu \mathrm{L}$ eluent volume was rejected because the eluate drop was too little due to fragmentation caused by hydrodynamic impedance in the KR. The best conditions found were 100 and $155 \mathrm{~cm}$ for KR with an eluent volume of 40 or $50 \mu \mathrm{L}$. Best precision was obtained using $100 \mathrm{~cm}$ length for KR and $40 \mu \mathrm{L}$ of eluent volume.

\section{Cross-Reactivity}

APDC is a chelating agent that can form complexes with many transition metals. To check the selectivity of our procedure, different experiments were performed in order to evaluate cross-reactivity. The metals studied were selected because they can form complexes and because they are present in seawater (14): Mo, Ni, Zn, Fe, V, Se, $\mathrm{Cu}, \mathrm{Sn}, \mathrm{Mn}, \mathrm{Co}, \mathrm{Sb}, \mathrm{Ag}, \mathrm{Cr}, \mathrm{Cd}, \mathrm{Pb}$, $\mathrm{Ga}$, and Bi. Moreover, Cr(III) has also been included in the study to check the efficacy of the separation and to discard a possible interchange of species. Different solutions of a synthetic seawater spiked with $0.1 \mu \mathrm{g} \mathrm{L}^{-1} \mathrm{Cr}(\mathrm{VI})$ and with three different concentration levels of the elements studied (at concentrations normally found in seawater) were treated using the preconcentration procedure proposed. The percentages of the analytical recoveries obtained for $\mathrm{Cr}(\mathrm{VI})$ in the presence of the different elements are listed in Table III. There were no significant interferences at the normal levels of these elements in seawater.

\section{Analytical Performance \\ Calibration. \\ Evaluation of Matrix Effects}

In order to check the linearity of the method, three different calibration graphs were performed: (a) an aqueous calibration, (b) a calibration in synthetic seawater, and (c) a standard addition calibration using a seawater sample treated with the preconcentration procedure proposed. In all cases, the levels of $\mathrm{Cr}(\mathrm{VI})$ used were: $0,0.05$, $0.10,0.15,0.2$, and $0.25 \mu \mathrm{g} \mathrm{L}^{-1}$. The equations obtained were:

Aqueous calibration:

Abs $=0.6331 \mathrm{C}+0.0005 \quad \mathrm{r}=0.999$

Calibration in synthetic seawater: Abs $=0.5417 \mathrm{C}+0.0102 \quad \mathrm{r}=0.999$

\section{Atomic Apectroscopy \\ 1 Vol. 32(1), Jan./Feb. 2011}

Standard addition calibration: Abs $=0.5949 \mathrm{C}+0.0313 \mathrm{r}=0.999$

After statistical comparison (95\% confidence range, Student's $t$-test), it was found that when the slopes are statistically different, it will be necessary to use the standard addition calibration.

To prepare the standard addition calibration, it is necessary to dilute

TABLE III

Effect of Different Elements in the Recovery of $0.1 \mu \mathrm{g} \mathrm{L} \mathrm{L}^{-1} \mathrm{Cr}$ (VI) Added to a Synthetic Seawater Sample

\begin{tabular}{|c|c|c|c|c|c|c|c|}
\hline Ion & $\begin{array}{c}\mathrm{SW}^{*} \\
\left(\mu \mathrm{g} \mathrm{L}^{-1}\right)\end{array}$ & $\begin{array}{l}\text { Conc. } \\
\left(\mu \mathrm{g} \mathrm{L}^{-1}\right)\end{array}$ & $\begin{array}{c}\text { Recovery } \\
(\%)\end{array}$ & $\begin{array}{c}\text { Ion } \\
\left(\mu \mathrm{g} \mathrm{L}^{-1}\right)\end{array}$ & $\begin{array}{c}\mathrm{SW}^{*} \\
\left(\mu \mathrm{g} \mathrm{L}^{-1}\right)\end{array}$ & $\begin{array}{l}\text { Conc. } \\
\left(\mu \mathrm{g} \mathrm{L}^{-1}\right)\end{array}$ & $\begin{array}{c}\text { Recovery } \\
(\%)\end{array}$ \\
\hline Mo(VI) & 10 & $\begin{array}{l}10 \\
100 \\
1000\end{array}$ & $\begin{array}{l}100.1 \\
106.0 \\
123.4\end{array}$ & $\mathrm{Mn}(\mathrm{II})$ & 0.40 & $\begin{array}{l}0.4 \\
1 \\
10\end{array}$ & $\begin{array}{l}100.6 \\
93.5 \\
96.9\end{array}$ \\
\hline $\mathrm{Ni}(\mathrm{II})$ & 6.60 & $\begin{array}{l}7 \\
10 \\
70\end{array}$ & $\begin{array}{l}97.2 \\
102.8 \\
120.9\end{array}$ & $\mathrm{Co}$ (II) & 0.39 & $\begin{array}{l}0.4 \\
1 \\
10\end{array}$ & $\begin{array}{l}97.6 \\
78.6 \\
81.6\end{array}$ \\
\hline $\mathrm{Zn}$ (II) & 5.00 & $\begin{array}{l}5 \\
10 \\
100\end{array}$ & $\begin{array}{l}98.92 \\
99.07 \\
93.77\end{array}$ & $\mathrm{Sb}$ (III) & 0.33 & $\begin{array}{l}0.4 \\
1 \\
10\end{array}$ & $\begin{array}{l}99.6 \\
97.7 \\
72.7\end{array}$ \\
\hline $\mathrm{Fe}(\mathrm{III})$ & 3.40 & $\begin{array}{l}4 \\
10 \\
100\end{array}$ & $\begin{array}{l}96.1 \\
96.5 \\
101.0\end{array}$ & $\operatorname{Ag}(I)$ & 0.28 & $\begin{array}{l}0.3 \\
1 \\
10\end{array}$ & $\begin{array}{l}105.0 \\
106.6 \\
105.1\end{array}$ \\
\hline As(III) & 2.60 & $\begin{array}{l}3 \\
10 \\
100\end{array}$ & $\begin{array}{l}103.9 \\
107.6 \\
103.3\end{array}$ & Cr(III) & 0.20 & $\begin{array}{l}0.2 \\
1 \\
10\end{array}$ & $\begin{array}{l}94.1 \\
105.5 \\
117.2\end{array}$ \\
\hline $\mathrm{V}(\mathrm{V})$ & 1.90 & $\begin{array}{l}2 \\
10 \\
100\end{array}$ & $\begin{array}{l}102.1 \\
100.6 \\
98.3\end{array}$ & $\mathrm{Hg}$ (II) & 0.15 & $\begin{array}{l}0.2 \\
1 \\
10\end{array}$ & $\begin{array}{l}100.6 \\
99.0 \\
95.5\end{array}$ \\
\hline $\mathrm{Al}(\mathrm{III})$ & 1.00 & $\begin{array}{l}1 \\
10 \\
100\end{array}$ & $\begin{array}{l}94.1 \\
93.5 \\
69.0\end{array}$ & $\mathrm{Cd}(\mathrm{II})$ & 0.11 & $\begin{array}{l}0.2 \\
1 \\
10\end{array}$ & $\begin{array}{l}104.2 \\
105,5 \\
100.5\end{array}$ \\
\hline $\mathrm{Se}(\mathrm{IV})$ & 0.90 & $\begin{array}{l}1 \\
10 \\
100\end{array}$ & $\begin{array}{l}96.7 \\
100.5 \\
105.6\end{array}$ & $\mathrm{~Pb}(\mathrm{II})$ & 0.03 & $\begin{array}{l}0.03 \\
0.1 \\
1\end{array}$ & $\begin{array}{l}100.8 \\
99.6 \\
107.7\end{array}$ \\
\hline $\mathrm{Cu}(\mathrm{II})$ & 0.90 & $\begin{array}{l}1 \\
10 \\
100\end{array}$ & $\begin{array}{l}98.6 \\
100.7 \\
93.8\end{array}$ & $\mathrm{Ga}$ (III) & 0.03 & $\begin{array}{l}0.03 \\
0.1 \\
1\end{array}$ & $\begin{array}{l}98.5 \\
93.9 \\
92.8\end{array}$ \\
\hline $\operatorname{Sn}(\mathrm{II})$ & 0.80 & $\begin{array}{l}0.8 \\
2 \\
10\end{array}$ & $\begin{array}{l}105.2 \\
94.3 \\
91.7\end{array}$ & $\mathrm{Bi}(\mathrm{III})$ & 0.02 & $\begin{array}{l}0.02 \\
0.1 \\
1\end{array}$ & $\begin{array}{l}95.2 \\
81.1 \\
88.1\end{array}$ \\
\hline
\end{tabular}

${ }^{*} \mathrm{SW}=$ total concentration of the element in the seawater sample. 
the sample which can produce contamination problems; moreover, this step increases the analysis time. In order to obtain a standard addition with less matrix effects, the three calibration graphs mentioned above were performed again but working only with a 1-minute preconcentration time. In this case, the equations obtained were:

Aqueous calibration:

Abs $=0.2830 \mathrm{C}+0.0005 \quad \mathrm{r}=0.998$

Calibration in synthetic seawater Abs $=0.2756 \mathrm{C}+0.0059 \quad \mathrm{r}=0.999$

Standard addition calibration: Abs $=0.2824 \mathrm{C}+0.0213 \quad \mathrm{r}=0.999$

After statistical comparison (95\% confidence range, Student's $t$-test), it was found that there are no statistical differences between the slopes. Thus, calibration with aqueous standards is possible.

\section{Sensitivity of the Method}

The limit of detection ( $3 \mathrm{SD} / \mathrm{m}$ ) and the limit of quantification $(10 \mathrm{SD} / \mathrm{m})$, where SD is the standard deviation of 11 measurements of a blank and $\mathrm{m}$ is the mean slope of the standard addition graph, were $7 \mathrm{ng} \mathrm{L}^{-1}$ and $23 \mathrm{ng} \mathrm{L}^{-1}$, respectively. These values are low enough to determine $\mathrm{Cr}(\mathrm{VI})$ in unpolluted seawater samples. The values obtained are similar to those reported by other authors (15) when using the same complex retained in a $\mathrm{KR}$ of $6.7 \mathrm{ng} \mathrm{L}^{-1}$, or when this complex is retained in a column reactor packed with PTFE beads of $8.8 \mathrm{ng} \mathrm{L}^{-1}$ (16).

\section{Repeatability of the Method}

The repeatability of the overall procedure was assessed by analyzing a seawater sample (spiked with $\left.0.2 \mu \mathrm{g} \mathrm{L}^{-1} \mathrm{Cr}(\mathrm{VI})\right) 11$ times using the on-line preconcentration method. The relative standard deviation was $4.4 \%$. This value is considered acceptable because many variables can affect the overall procedure.

\section{Recovery of the Method}

Analytical recovery was assessed for four concentration levels, after spiking different aliquots for the same seawater sample with 0.05 , $0.10,0.15$, and $0.20 \mu \mathrm{g} \mathrm{L}^{-1}$ of Cr(VI). The analytical recovery obtained showed a mean \pm standard deviation of $99.3 \pm 1.7 \%$.

In order to check the possible interference of $\mathrm{Cr}$ (III), another recovery study with a seawater sample spiked with a fixed amount of $\mathrm{Cr}$ (III) $\left(1 \mu \mathrm{g} \mathrm{L}^{-1}\right)$ and with different amounts of $\mathrm{Cr}(\mathrm{VI})$ of $0.05,0.10$, 0.15 , and $0.20 \mu \mathrm{g} \mathrm{L}^{-1}$ was performed. The recovery obtained was $98.8 \pm$ $2.5 \%$ which demonstrates that $\mathrm{Cr}$ (III) was not retained in the KR.

\section{Preconcentration Factor and Adsorption Efficiency}

The enrichment factor was assessed by comparing the slope of the linear portion of the calibration curve before and after preconcentration (14). For this, different solutions of ethanol spiked with different $\mathrm{Cr}(\mathrm{VI})$ levels ranging from 0-10 $\mu \mathrm{g} \mathrm{L}^{-1}$ were directly injected into the graphite furnace. Afterwards, calibration was carried out for the preconcentration procedure. The equations obtained were:

Direct calibration:

Abs $=0.0157 \mathrm{C}+0.0036 \quad \mathrm{r}=0.998$

Standard addition with preconcentration:

Abs $=0.4850 \mathrm{C}+0.0045 \quad \mathrm{r}=0.999$

The preconcentration factor was 31. Another parameter important for characterizing a preconcentration method using KR is the adsorption efficiency. To obtain this value, a comparison between the theoretical preconcentration factor and the experimental preconcentration factor must be performed. The theoretical preconcentration factor was 125 , and the adsorption efficiency obtained was $24.8 \%$.

\section{APPLICATIONS}

The proposed method was applied to study the levels of Cr(VI) concentration in seawater samples from the Ria de Arousa Estuarine in Galicia (Northwestern Spain). Twenty-six different samples were collected and stored in acid precleaned polyethylene bottles before analysis. The samples were analyzed in triplicate using aqueous calibration. Chromium(VI) was detected in all samples and the concentration range found was between 0.03-0.09 $\mu \mathrm{g} \mathrm{L} \mathrm{L}^{-1}$.

\section{CONCLUSION}

A fast, simple, inexpensive, sensitive, and selective flow injection preconcentration system, coupled with an electrothermal atomic absorption spectrometry (ETAAS) system, was developed to perform Cr(VI) determination in seawater samples. The proposed method is very robust and simple to perform, valid to handle complex sample matrices without problems (such as seawater with very high salt concentrations). The sampling frequency was 8 samples $\mathrm{h}^{-1}$ (using three replicates per analysis). The detection limit (3SD) was $7 \mathrm{ng} \mathrm{L}^{-1}$. The precision (RSD $\mathrm{n}=11$ ) was $4.4 \%$, and the recovery was $99.3 \pm$ $1.70 \%$. The good analytical capabilities and practical advantages of the proposed method make it a reliable alternative to methods such as HPLC-ICP-MS using more expensive and complicated instrumentation.

The method was applied to the Cr(VI) determination in seawater samples from the Ria de Arousa Estuarine in Galicia (Northwestern Spain), resulting in Cr(VI) concentrations ranging from $0.03-0.09 \mu \mathrm{g} \mathrm{L}^{-1}$. 


\section{Appectroscopy \\ 1 Vol. 32(1), Jan./Feb. 2011}

\section{ACKNOWLEDGMENTS}

This work is a contribution to the project financed by the Ministerio de Ciencia y Technología, Spain (ref. REN2002-01941), and by the Xunta de Galicia, Grupos de Referencia Competitivos 2007/047.

Received October 23, 2010

\section{REFERENCES}

1. E. Merian (Ed.), Metals and Their Compounds in the Environment, VCH, New York, USA (1991).

2. R. Cornelis, J. Caruso, H. Crews, and K. Heumann (Eds.), Handbook of Elemental Speciation II. Species in the Environment, Food, Medicine and Occupational Health, John Wileys \& Sons, Chichester, U.K. (2005).

3. L.P. Ebdon, R. Cornelis, H. Crews, O. Donard, and P. Quevauviller, Trace Element Speciation for Environmental, Food and Health, Royal Society of Chemistry, London, England (2001).

4. Directive of the Council of 10 November 1979 (79/923/CEE), Relative to Quality of Water for Keeping Mollusc, OFF. J. Eur. Comm., No. L 281 (1979).

5. R.E. Cranston and J.E. Murray, Anal. Chim. Acta 99, 275 (1978).

6. K. Isshiki, Y. Sohrin, H. Karatani, and E.Narayama, Anal. Chim. Acta 224, 55 (1989).
7. M. Sperling, X. Yin, and B. Welz, Analyst 117, 629 (1992).

8. T.P. Rao, S. Karthikeyan, B. Vijayalekshmy, and C.S.P. Iyer, Anal. Chim. Acta 369, 69 (1998).

9. S.C. Nielsen, S. Sturup, H. Spliid, and E.H. Hansen, Talanta 49, 1027 (1999).

10. M. Sperling, X.P. Yan, and B. Welz, Spectrochim. Acta, Part B, 51 , 1891 (1996)

11. Z.L. Fang, S.K. Xu, L.P. Dong, and W.Q. Li, Talanta 41, 2165 (1994).

12. X.P. Yan, W. Van Mol, and F. Adams, Analyst 121, 1061 (1996).

13. P. Herbello-Hermelo, M.C. BarcielaAlonso, A. Bermejo Barrera, and P. Bermejo-Barrera, J. Anal. At. Spectrom. 20, 662 (2005)

14. R. Chester, Marine Geochemistry, $2^{\circ}$ Ed., Blackwell Science, Ltd.: Malden, USA, 2003

15. S.C. Nielsen and E.H. Hansen, Anal.Chim. Acta 422, 47 (2000).

16. W. Som-Aum, S. Liawruangrath, and E.H. Hansen, Anal. Chim. Acta 463, 99 (2002). 